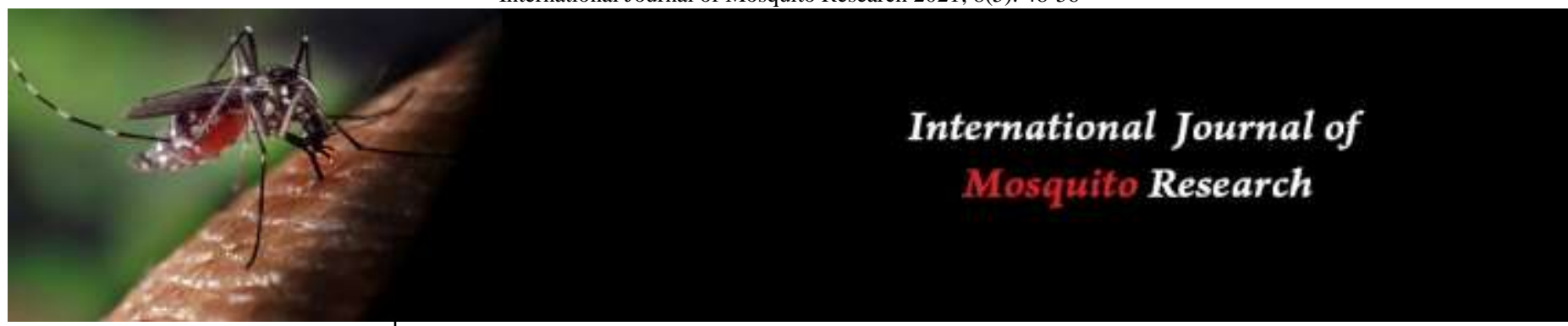

ISSN: 2348-5906

CODEN: IJMRK2

IJMR 2021; 8(5): 48-56

(C) 2021 IJMR

www.dipterajournal.com

Received: 22-06-2021

Accepted: 27-07-2021

Siddaiah Madpathi

Research Scholar, Department of

Zoology, University College of

Science, Osmania University,

Hyderabad, Telangana, India

Reddya Naik Bannoth

Professor, Department of

Zoology, University College of

Science, Osmania University,

Hyderabad, Telangana, India
Corresponding Author: Siddaiah Madpathi

Research Scholar, Department of Zoology, University College of Science, Osmania University, Hyderabad, Telangana, India

\section{The efficacy of Ximenia americana plant mediated silver nanoparticles against dengue vector mosquito larvae [Aedes (Stegomyia) aegypti (Linnaeus, 1762) (Diptera: Culicidae)]}

\author{
Siddaiah Madpathi and Reddya Naik Bannoth
}

DOI: $\underline{\text { https://doi.org/10.22271/23487941.2021.v8.i5a.563 }}$

\section{Abstract}

Nanotechnology is an emerging technology and day to day expanding its roots of knowledge to various branches of Science and fulfilling human conveniences. To manage vector populations, new tools have been emerging through nanotechnology. Nanoparticles possess peculiar toxicity mechanisms due to surface volume ratio, and this may actively contribute to their excellent larvicidal potential against Aedes aegypti mosquito. Dengue is a mosquito borne disease and making major public health issue worldwide. Aedes (Stegomyia) aegypti (Linnaeus, 1762) prefers to bread in artificial containers, and anti-larval measures with Ximenia americana L. (Olacaceae) leaf mediated silver nanoparticles (AgNPs) proves to be a potential substitute for the existing organophosphorus insecticides like temephos, malathion and fenthion etc., for mosquito control programme. Larvae were exposed to varying concentrations of plant extracts and synthesized silver nanoparticles for 24 hours. From the results, it was found that plant extracts showed moderate larvicidal effects (LC50 at 179.87 and LC90 at $376.77 \mathrm{ppm}$ ) but, the synthesized silver nanoparticles had found to be toxic to larvae at LC50 (0.63 ppm) and LC90 (1.20 ppm). This research highlighted that, the Ximenia americana leaf mediated AgNPs are an efficient and eco-friendly agents against Ae. aegypti mosquito, though the laboratory studies have shown the promising results, yet their efficacy in the field is to be tested for effective mosquito larval control.

Keywords: Aedes aegypti, Ximenia americana L. (Olacaceae), Silver nanoparticles (AgNPs)

\section{Introduction}

The incidence of dengue has grown dramatically around the world in recent decades and making major public health concern worldwide ${ }^{[1-6]}$. One recent estimate indicates 390 million dengue infections per year (95\% credible interval 284-528 million), of which 96 million (67136 million) manifest clinically (with any severity of disease) ${ }^{[7,8]}$. Another study on the prevalence of dengue estimates that 3.9 billion people in 128 countries are at risk of infection with dengue viruses ${ }^{[9]}$. Dengue is widespread throughout the tropics with local variations in risk influenced by temperature, rainfall and unplanned rapid urbanization. In India, a total of 101192 cases and 172 deaths were recorded due to dengue for the year of 2018 and in 2019 it was increased to 136422 whereas the death rate was decreased to $1322^{[10]}$.

Aedes (Stegomyia) aegypti (Linnaeus, 1762) is a day-time feeder and prefers to breed in manmade containers and thrives in urban and peridomestic environments where it transmits the Dengue virus to humans ${ }^{[11]}$. This mosquito also transmits Chikungunya, Yellow fever and Zika infection. Long time exposure to various synthetic insecticides leads to the occurrence of the resistance in vector mosquitoes ${ }^{[12]}$. Acquired insecticide resistance has reduced the ability of insecticides to control mosquito vectors ${ }^{[13-15]}$. Synthetic insecticides had unique properties, such as long time persistence, more residual activity and biomagnifications. These properties could be hazardous and lead to the chronic effects in non-target organisms, and the environment ${ }^{[16-18]}$. Plant mediated insecticides are an outstanding alternative for the synthetic insecticides ${ }^{[19]}$. Number of phytochemicals with biological activity against larval and adult mosquitoes has been described ${ }^{[20-24]}$.

Involvement of nanotechnology in arthropod vector control led to emergence of new routes such as green synthesis of metallic nanoparticles against mosquito and it has been succeeded 
and giving the best solutions to mosquito menace ${ }^{[25-27]}$. The plant-mediated synthesis of silver nanoparticles; is an ecofriendly approach, more advantageous over chemical and physical methods, cheap, single-step and does not require high pressure, energy, temperature, or extremely toxic chemicals ${ }^{[28,29]}$. Ximenia americana belongs to the family Olacaceae, commonly known as sea lemon. It is a bush forming shrub and small tree and found on banks of rivers and moist areas throughout India. The aim of this study is to determine the biological activity of Ximenia americana leaf extract against Ae. aegypti mosquitoes. In the Laboratory the efficacy of leaf extract was tested with crude as well as plant mediated silver nanoparticles with $3^{\text {rd }}$ and $4^{\text {th }}$ instar larvae.

\section{Materials and Methods}

\subsection{Mosquito collection and culture}

Ae. aegypti larvae and pupae were collected by the dipping method from natural habitats, in and around Osmania University, Hyderabad, Telangana, India ${ }^{[30]}$. Rearing conditions for all mosquitoes were maintained $\left(27 \pm 2{ }^{\circ} \mathrm{C}, 75-\right.$ 85\% RH, and L14: D10 photoperiod). According to the manual for mosquito rearing and experimental techniques published by American Mosquito Control Association larvae were reared to adulthood in the mosquito culture room in two liter of water in white enamel trays $(30 \mathrm{~cm}$ long $\times 25 \mathrm{~cm}$ wide $\times 6 \mathrm{~cm}$ deep) where they were provided a daily food mix comprising three parts brewer's yeast and one part dog biscuit [31]. Pupae were placed into screened cages $(23 \mathrm{~cm}$ long $\times 23$ $\mathrm{cm}$ wide $\times 23 \mathrm{~cm}$ deep). When imago emerged after 24 hours; they were identified followed by standard keys [32-34], transferred into glass cages $(30 \mathrm{~cm}$ long $\times 30 \mathrm{~cm}$ wide $\times 30 \mathrm{~cm}$ deep) and provided with $10 \%$ sucrose solution (in water) via a piece of cotton. After mating, female mosquitoes were allowed access to feed on nude mice for blood feeding. Eggs were collected through ovitraps and this pure culture was reared again to get the $F_{1}$ generation and finally these larvae were used for bioassay.

\subsection{Plant material collection and preparation of extract:}

Plant material collection and extraction has been done by standard methodologies [35, 36]. Ximenia americana plant leaves were collected from Osmania University, Hyderabad, Telangana, India (Latitude: 17.427 and Longitude: 78.53448). Taxonomic identification carried out at the Department of Botany, Osmania University, Hyderabad, India. A voucher specimen was deposited in the Medical Entomology Laboratory (ID: NHMZD273), Department of Zoology, Osmania University, Hyderabad.

Fresh leaves of Ximenia americana were collected, washed several times with tap water to remove the dust particles and then shade dried for two weeks at $27{ }^{\circ} \mathrm{C}$ to remove the residual moisture and grinded to form fine powder. Then plant extract was prepared by mixing $25 \mathrm{~g}$ of leaf powder with 250 $\mathrm{mL}$ of deionized water in a $500 \mathrm{~mL}$ of (Borosil, India) conical flask. The solution was mixed for every 3 hours with fresh glass rod. After 48 hours the solvent color changed from moderate to fully dark; it indicates dissolved state of plant material. Plant material was filtered with the help of What's man No. 1 filter paper, and crude extract was stored at $4{ }^{\circ} \mathrm{C}$ for further analysis. Presence of alkaloids was confirmed using Mayer's test and Wagner's test. Then the solution was used for the reduction of silver ions $\left(\mathrm{Ag}^{+}\right)$to silver nanoparticles $\left(\mathrm{Ag}^{\circ}\right)$.

\subsection{Synthesis of Silver Nanoparticles}

Biosynthesis of silver nanoparticles has been carried out by standard methodologies ${ }^{[37-40]}$. In a typical synthesis of silver (Ag) nanoparticles, $20 \mathrm{ml}$ of leaf extract was added to reduce $80 \mathrm{ml}$ of $1 \mathrm{mM} \mathrm{AgNO}_{3}$ (bought from Sigma Aldrich Bangalore) aqueous solution and kept at room temperature. For the reproducibility experiment was done in triplicate.

\subsection{Characterization of AgNPs}

The bioreduction of pure $\mathrm{Ag}^{+}$ions was monitored by measuring the UV-visible spectra (UV-spec) of the reaction medium [Shimadzu 2600 - (TCC)]. For FTIR measurements, the Silver nanoparticles solution was centrifuged at 10,000 rpm for $30 \mathrm{~min}$. The pellet was washed three times with $20 \mathrm{ml}$ of deionized water to get rid of the free proteins or enzymes that are not capping the silver nanoparticles. The samples were dried and grinded with $\mathrm{KBr}$ pellets and analysed on a Bruker Optics (Germany made) Tensor-27 model in the diffuse reflectance mode operating at a resolution of $0.4 \mathrm{~cm}^{-1}$. The size and shape of silver nanoparticles have been visualized through a scanning electron microscope (SEM). Presence of elemental study was carried out by using EDS. Crystalline nature of AgNPs was studied through X-ray diffraction (XRD). GC-MS analysis has been carried out by the SHIMADZU QP2010, an oven temperature from 50 to $280{ }^{\circ} \mathrm{C}$ at $4{ }^{\circ} \mathrm{C} / \mathrm{min}$ and held at this temperature for $5 \mathrm{~min}$; inlet and interface temperatures were $250{ }^{\circ} \mathrm{C}$ and $280{ }^{\circ} \mathrm{C}$, respectively. Carrier gas was $\mathrm{He}$ at a flow rate of $1.0 \mathrm{ml} / \mathrm{min}$ (constant flow). $0.2 \mathrm{ml}$ of sample was injected under a split of 20:1. EIMS: electron energy, $70 \mathrm{eV}$. Interpretation of mass spectrum GC-MS was conducted using a database of NIST, having more than 62,000 patterns. The spectrum of the known compounds was compared with the NIST library.

\subsection{Bioassay}

Bioassay test was performed according to WHO guidelines [41], with different concentrations to assess the larvicidal activity. Percentage mortality was calculated as follows:

Percentage mortality $=($ Number of dead individuals $/$ Number of treated individuals $) \times 100$

\subsection{Statistical analysis}

The average larval mortality data were subjected to Probit analysis (FORTRAN) for calculating LC50 and LC90 ${ }^{[42]}$.

\section{Results}

After 1 hour the color of the solution changed from colorless to honey brown (Figure-1) indicating the formation of silver nanoparticles and this was confirmed by UV-visible spectroscopy. At 60 minutes a peak value at $435 \mathrm{~nm}$ with intensity of 0.06 was observed corresponding to AgNPs (Figure-2). Figure-3 illustrates the X-ray diffraction pattern with three characteristics of diffraction peaks for the AgNPs synthesized from the aqueous leaf extract of Ximenia americana. Bragg reflections with $2 \theta$ values of $40.63^{0}, 45.74^{0}$, and $77.50^{\circ}$ were indexed for the planes (111), (200) and (311) respectively. These Bragg refractions were in agreement with reference pattern of JCPDS NO.04-0783 and thus conforms the synthesized silver nanoparticle, which were crystalline in nature (size $27.01 \mathrm{~nm}$ ) and of face centered cubic (FCC) crystal lattice (Figure-3).

Infra-red (IR) spectra of AgNPs synthesized using Ximenia americana aqueous leaf filtrate after bio reduction of silver obtained by FTIR were recorded between 400 and $4000 \mathrm{~cm}^{-1}$ (Figure-4). Troughs were observed at $3444.98 \mathrm{~cm}^{-1}, 3421.83$ 
$\mathrm{cm}^{-1}, 2922.25 \mathrm{~cm}^{-1}, 2854.74 \mathrm{~cm}^{-1}, 2333.94 \mathrm{~cm}^{-1}$ and 1629.90 $\mathrm{cm}^{-1}$. The intense band at $3444.98 \mathrm{~cm}^{-1}$ is corresponds to $\mathrm{O}-\mathrm{H}$ stretching, $3421.83 \mathrm{~cm}^{-1}$ is O-H Medium stretching, 2922.25 $\mathrm{cm}^{-1}$ asymmetric stretching vibration of $\mathrm{CH}_{2}$ of acyl chains (lipids), $2854.74 \mathrm{~cm}^{-1}$ is corresponding to $\mathrm{CH}_{2}$ symmetric stretching, $2333.94 \mathrm{~cm}^{-1}$ is $\mathrm{O}-\mathrm{H}$ stretching, the band at $1629.90 \mathrm{~cm}^{-1}$ is corresponds to amide-I. It is observed from the spectra of silver nanoparticles the appeared bands at 1629.90 and 3444.98 which are due to amide-I and hydroxyl group that are responsible for reducing the $\mathrm{Ag}^{+}$ions to atoms (Figure-4).

According to the scanning electron micrograph, the morphology of the AgNPs was observed and approximately spherical. In the analysis by energy dispersive spectroscopy (EDS) of the AgNPs the presence of elemental metal signal was confirmed (Figure-5A and B). AFM data analyzed by NOVA-TX software highlighted that Ximenia americana leaf mediated AgNPs has shown a size ranging from 10 to $90 \mathrm{~nm}$, with most of them falling within range 10 to $90 \mathrm{~nm}$ (Figure$6 \mathrm{~A}$ and B). From the GC-MS analysis the active ingredient in the synthesized silver nanoparticle responsible for larvicidal activity was found to be 2-propanone (CAS) Acetone \$\$ Propa (Figure-7). LC50 and LC90 were recorded at 179.87 and $376.77 \mathrm{ppm}$ with Ximenia americana, whereas synthesized silver nanoparticles had shown LC50 at 0.63 and LC90 at 1.20 ppm (Table-1, 2 and Figure-8, 9).

\section{Discussion}

The biofabrication of the mosquitocidal silver nanoparticles is rapid, eco-friendly and cost-effective. AgNPs have excellent anti-mosquito larvicidal activity against third instar larvae of Ae. aegypti. Phytochemicals are botanicals which are naturally occurring insecticides obtained from floral resources. Applications of phytochemicals in mosquito control have been in use since the 1920's [43], but the discovery of synthetic insecticides such as DDT in 1939 side tracked the application of phytochemicals in mosquito control programmes. After facing several problems due to injudicious and over application of synthetic insecticides in nature, refocus on phytochemicals that are easily biodegradable and have no ill-effects on non-target organisms was appreciated. Safe and efficacious insecticides of plant origin have gained importance in recent years and are considered as less hazardous to human health. Studies on the larvicidal action of terrestrial plant extracts against the mosquito larvae were carried out tremendously. Many authors have studied the larvicidal action of terrestrial plant extracts against different mosquito larvae at very high concentrations of the plant extracts for achieving significant mortality of mosquito larvae [44].

Phytochemicals being derived from plant sources can act as larvicide, insect growth regulators, repellent and oviposition attractant and have different activities observed by many researchers. However, insecticides of plant origin have been extensively used on agricultural pests and to a very limited extent, against insect vectors of public health importance. From the results, it was found that plant crude extract showed moderate (LC50 at 179.87 and LC90 at 376.77ppm) larvicidal effect but, the synthesized silver nanoparticles had found to be toxic against mosquito larvae at LC50 (0.63ppm) and LC90 (1.20ppm). The research findings are in alignment with previously reported research studies. Santhosh kumar et al., (2011) synthesized AgNPs using aqueous crude extract of Nelumbo nucifera and tested its efficacy against $C x$. quinquefasciatus. $\mathrm{LC}_{50}$ and LC90 values were recorded at
0.69 and $3.59 \mathrm{ppm}{ }^{[45]}$. Turbinaria ornate mediated AgNPs were synthesized, used against Ae. aegypti and $\mathrm{LC}_{50}$ was recorded at $0.738 \mu \mathrm{g} / \mathrm{mL}{ }^{[46]}$. Azarudeen et al., (2017) synthesized AgNPs using Merremia emarginata, and got $\mathrm{LC}_{50}$ at $9.20 \mu \mathrm{g} / \mathrm{mL}$ against Ae. aegypti and $10.02 \mu \mathrm{g} / \mathrm{mL}$ for $C x$. quinquefasciatus ${ }^{[47]}$. Govindarajan et al., (2017) used Hugonia mystax to synthesize the AgNPs and got $\mathrm{LC}_{50}$ at $15.56 \mu \mathrm{g} / \mathrm{mL}$ for Ae. aegypti and $17.46 \mu \mathrm{g} / \mathrm{mL}$ for $C x$. quinquefasciatus ${ }^{[48]}$. Curcuma zedoaria mediated AgNPs were tested against $C x$. quinquefasciatus and $\mathrm{LC}_{50}$ was recorded at $0.64 \mathrm{ppm}^{[49]}$. Aina et al., (2019) tested the toxicity of Chasmanthera dependens mediated AgNPs against Ae. aegypti and $\mathrm{LC}_{50}$ was recorded at $7.15 \mu \mathrm{g} / \mathrm{mL}{ }^{[50]}$. Benelli et al., (2018a) synthesized AgNPs using Acacia caesia and tested the larvicidal toxicity against Ae. albopictus and got $\mathrm{LC}_{50}$ value at $11.32 \mu \mathrm{g} / \mathrm{mL}{ }^{[51]}$. Muthukumaran et al., (2015) concluded that the aqueous crude extracts and synthesized silver nanoparticles of Gmelina asiatica had shown the toxicidal effect on late $3^{\text {rd }}$ instar of $C x$. quinquefasciatus at $\mathrm{LC}_{50}$ value of $139.17 \mathrm{mg} / \mathrm{l}$ and $\mathrm{LC}_{90}$ value was $243.39 \mathrm{mg} / \mathrm{l}^{[52]}$. Mondal et al., (2019) synthesize silver nanoparticles with Colocasia esculenta as a reducing agent and to evaluate their effect against Culex quinquefasciatus the $\mathrm{LC}_{50}$ and $\mathrm{LC}_{90}$ synthesized silver nanoparticles were $5.17 \mathrm{mg} / \mathrm{L}$ and 17.32 $\mathrm{mg} / \mathrm{L}^{[53]}$.

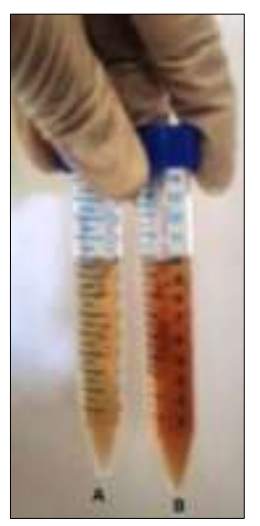

Fig 1: Showing the photograph (A-leaf extract, B-silver nanoparticles after 1 hour) of leaf extract and AgNPs of the Ximenia americana.

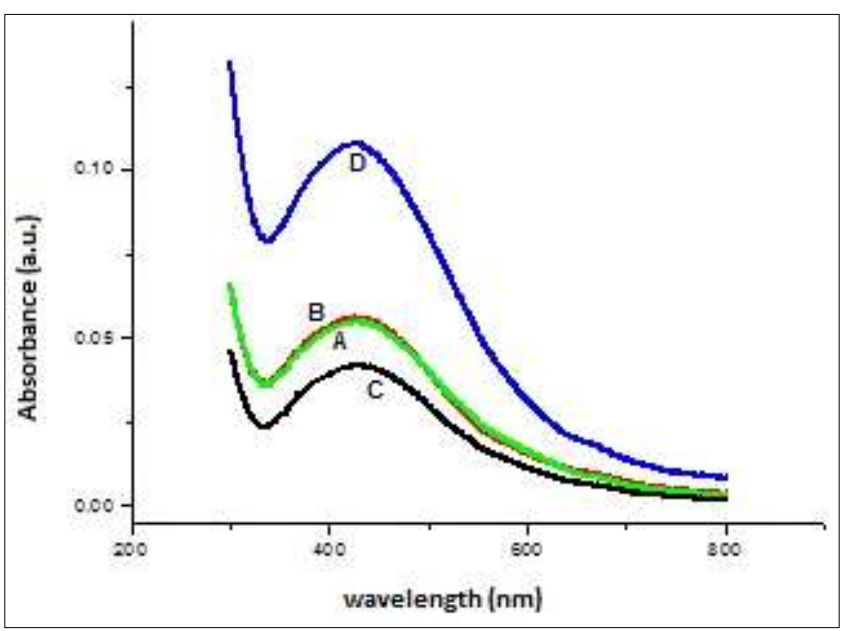

Fig 2: Showing the UV-visible spectra recorded as a function of time of reaction of an aqueous solution of $1 \mathrm{mM} \mathrm{AgNO}_{3}$ with the leaf extract of Ximenia americana (60 minutes). (a) 30 minutes; (b) 60 minutes; (c) 90 minutes; (d) 120 minutes. 


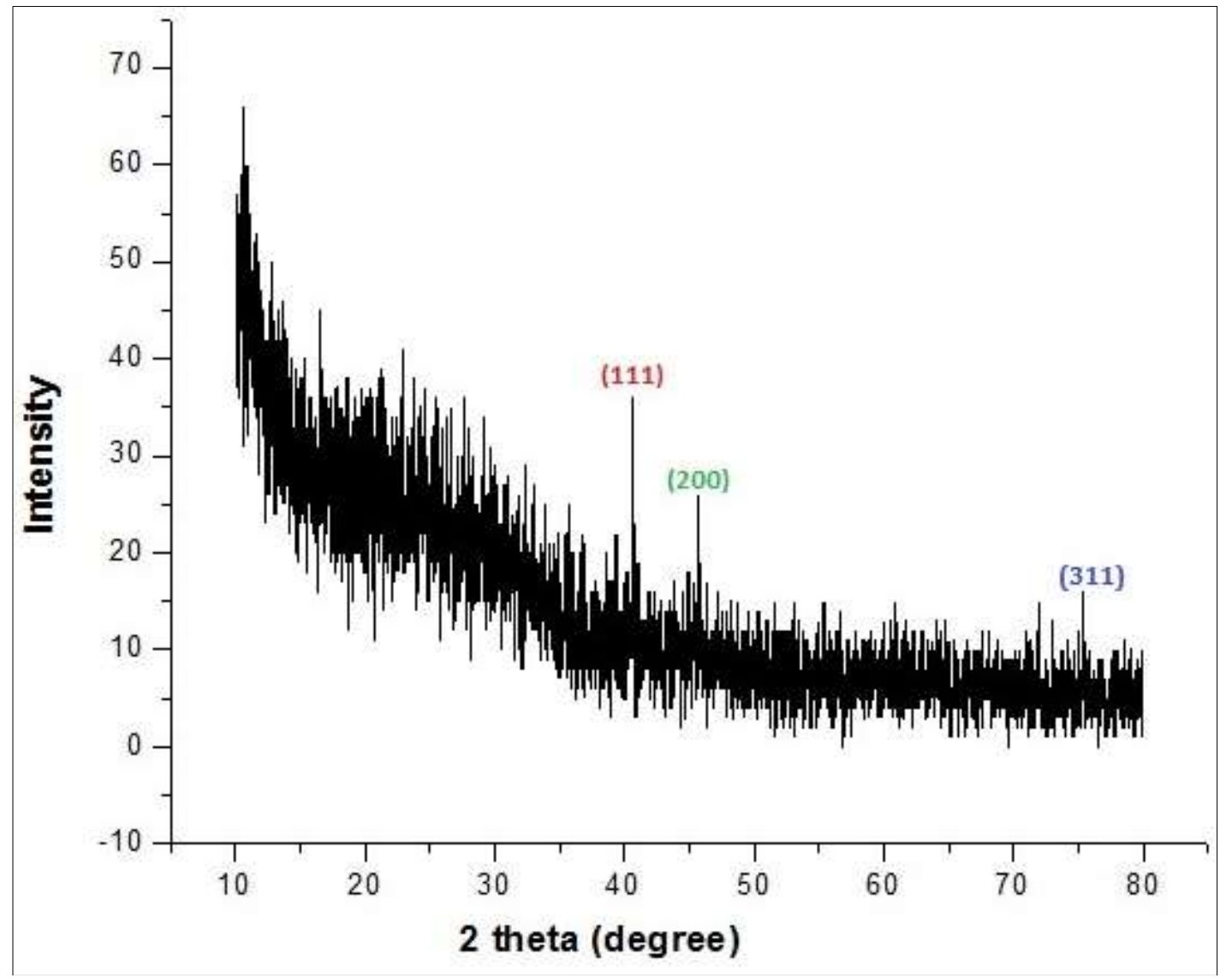

Fig 3: Showing the XRD patterns of synthesized silver nanoparticles of Ximenia americana.

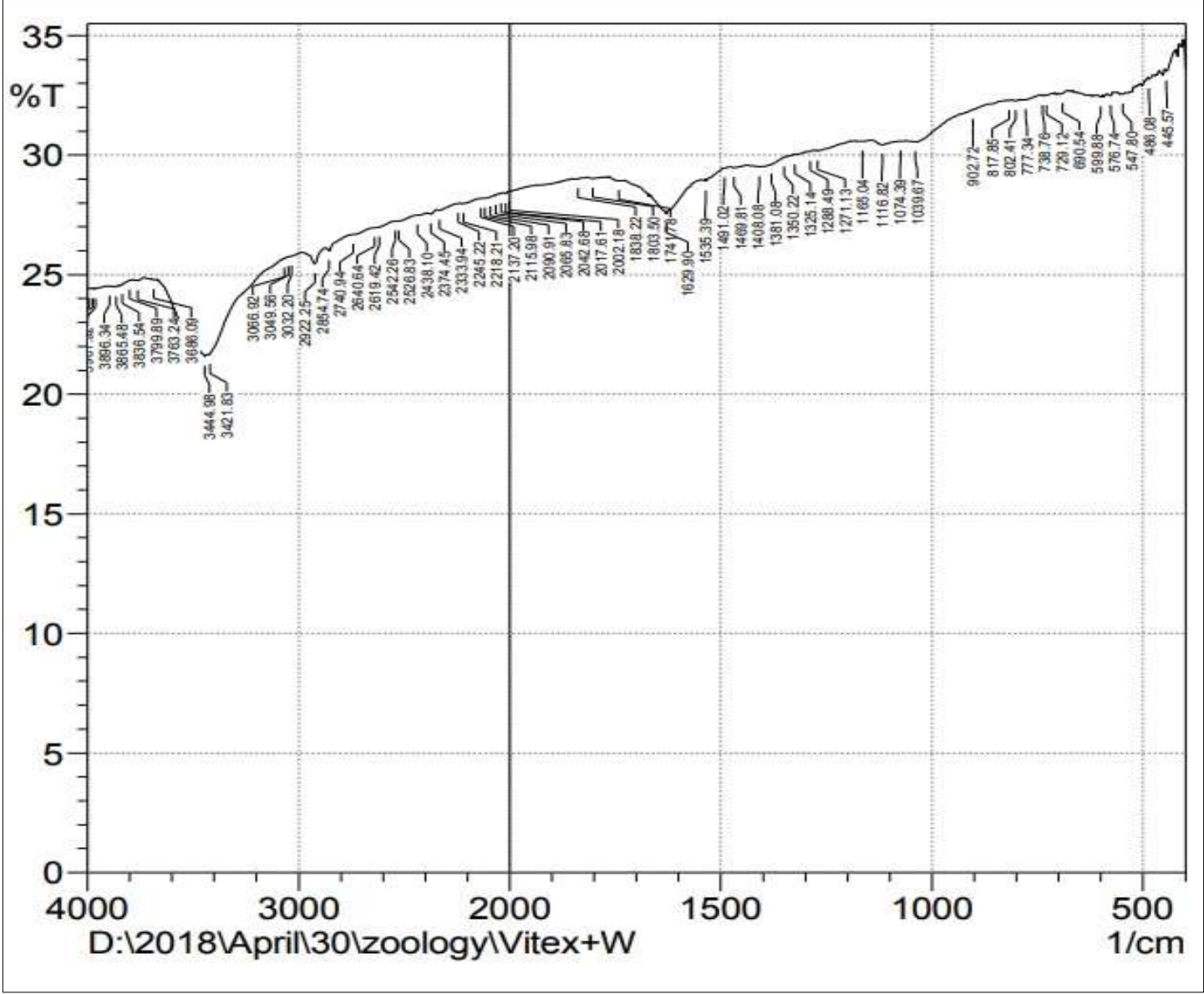

Fig 4: Showing the FT-IR spectrum of AgNPs prepared from the Ximenia americana plant extract. 

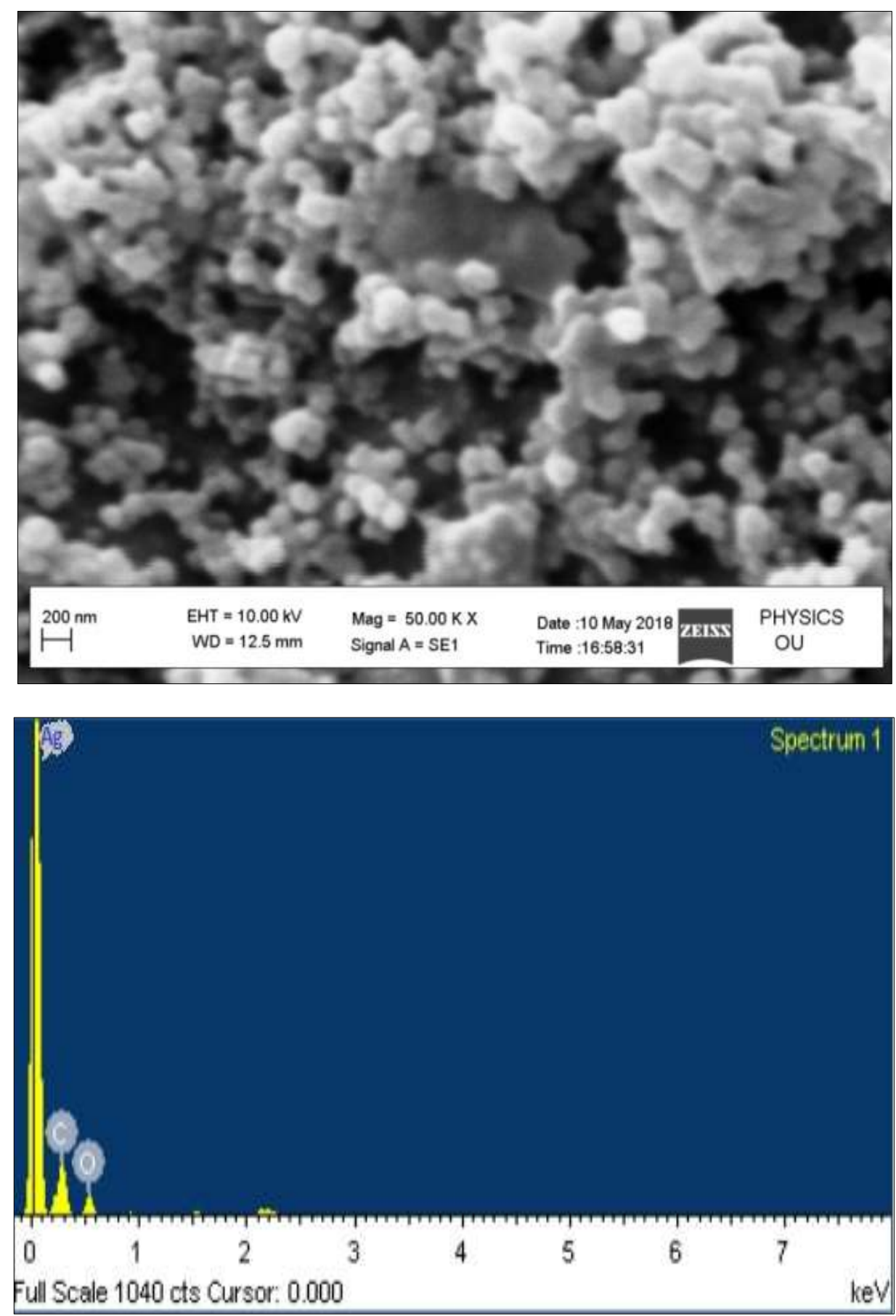

Fig 5: Showing the the SEM image (A) and EDS profile (B) of bio-reduced silver nanoparticles.

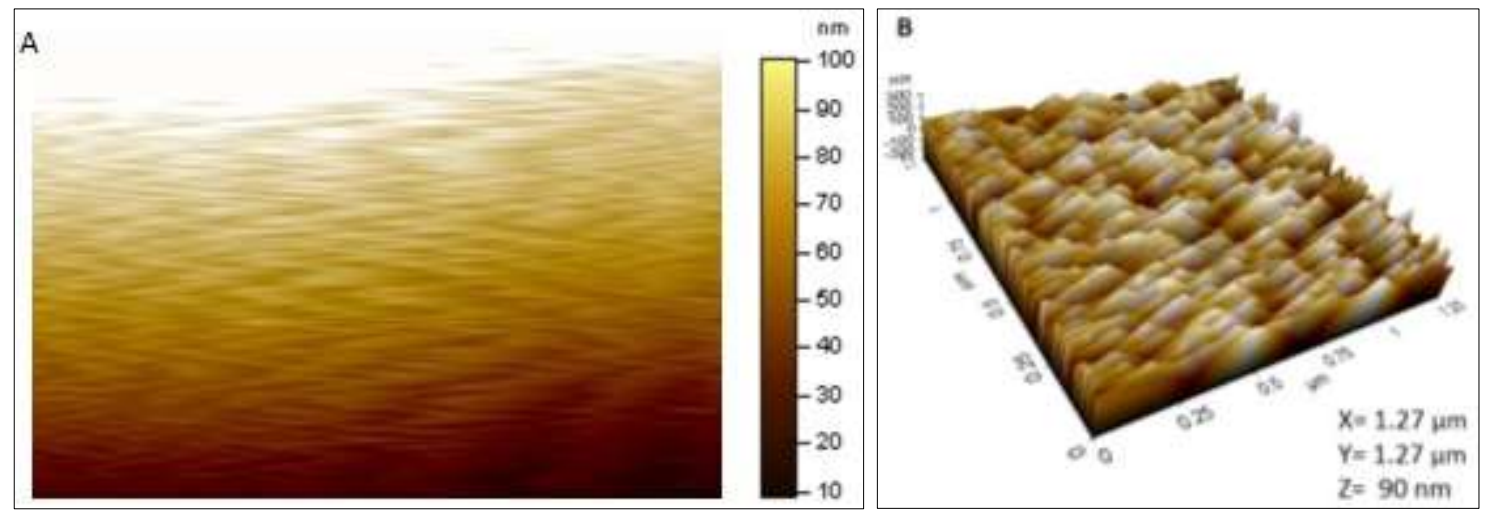

Fig 6: (A) $2.5 \mu \mathrm{m}$ resolution studies of 10-90 nm size, sperical shaped, polydispersed particles, (B) 3D image of silver nanoparticles analyzes by NOVA-TX software. 


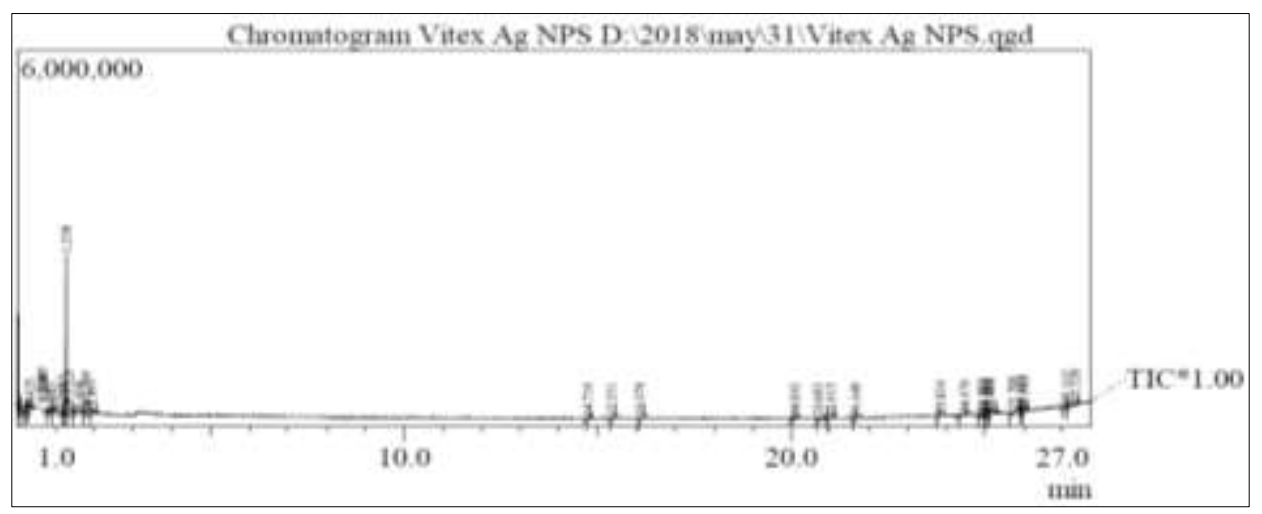

\begin{tabular}{|c|c|c|c|c|c|c|}
\hline \multirow{2}{*}{\multicolumn{2}{|c|}{$\mathrm{k} \# \mathrm{R}$. Time }} & \multirow[b]{2}{*}{ Area } & \multirow[b]{2}{*}{ Area\% } & \multicolumn{3}{|r|}{ Peak Report TIC } \\
\hline & & & & Height & $\mathrm{sse} / \mathrm{z}$ & Name \\
\hline 1 & 0.045 & 376698 & 4.30 & 152041 & 44.00 & 1-Gala-1-ido-octose $\$ \$$ \\
\hline 2 & 0.208 & 568588 & 6.49 & 124435 & 44.00 & 1,3,5-Triazin- $(1 \mathrm{H})$-one, 4,6-bis (ethyl \\
\hline 3 & 0.240 & 333101 & 3.80 & 125564 & 40.00 & Piperidine, 1-nitro- (CAS) N-Nitropip \\
\hline 4 & 0.325 & 168757 & 1.93 & 41440 & 42.05 & ALPHA-D4-HEXAMETHYLENE O \\
\hline 5 & 0.783 & 43664 & 0.50 & 15089 & 44.00 & Benzeneethanamine, alpha.-methyl- \\
\hline 6 & 0.883 & 75199 & 0.86 & 15505 & 40.00 & Ethanol, 2,2-dichloro- (CAS) 2,2-Dich \\
\hline 7 & 1.167 & 343932 & 3.93 & 159836 & 40.00 & BETA.-IONONE EPOXIDE $\$ \$$ \\
\hline 8 & 1.258 & 2321655 & 26.51 & 2527057 & 43.00 & 2-Propanone (CAS) Acetone $\$ \$$ propa \\
\hline 9 & 1.325 & 991120 & 11.32 & 249027 & 44.00 & (S)-(+)-1-Cyclohexylethylamine \$\$ \\
\hline 10 & 1.600 & 595666 & 6.80 & 57494 & 43.05 & Acetic acid (CAS) Ethylic acid \$\$ Vir \\
\hline \begin{tabular}{|l|}
11 \\
\end{tabular} & 1.769 & 1377653 & 15.73 & 217283 & 45.05 & 3-hydroxy-2-butanone \$\$ ACETOIN \$ \\
\hline 12 & 1.891 & 292524 & 3.34 & 89081 & 45.05 & 2-Butanone, 3-hydroxy- (CAS) Acetol \\
\hline 13 & 14.716 & 30432 & 0.35 & 12834 & 39.95 & 2-Pyrrolidinethione (CAS) Thiopyrrol \\
\hline 14 & 15.351 & 50298 & 0.57 & 14692 & 44.00 & 1,1-Cyclopropanedicarboxamide $\$ \$$ \\
\hline 15 & 16.074 & 70683 & 0.81 & 18389 & 44.00 & 6-Dimethyl(trimethylsilyl) silyloxytetr: \\
\hline 162 & 20.092 & 53522 & 0.61 & 16024 & 44.05 & Cystine $\$ \$ 1-$ Cystine $\$ \$$. beta.,.beta.'-1 \\
\hline 17 & 20.683 & 100461 & 1.15 & 15272 & 44.00 & Imidazole, 2-amino-5-[(2-carboxy)vin] \\
\hline 186 & 21.015 & 102243 & 1.17 & 14927 & 44.00 & 5-Nitro-3-nitrylpyridone-2-(1H) \$\$ \\
\hline
\end{tabular}

\begin{tabular}{|c|c|c|c|c|c|}
\hline ik\#R.Time & \multicolumn{2}{|c|}{\begin{tabular}{l|l} 
Area & Area $\%$
\end{tabular}} & \multicolumn{2}{|c|}{ HeightBase $\mathrm{m} / \mathrm{z}$} & Name \\
\hline \begin{tabular}{|l|l|}
19 & 21.649 \\
\end{tabular} & 32490 & 0.37 & 17422 & 44.00 & Benzeneethanamine, 4-chloro-.alpha.- \\
\hline 2023.834 & 33384 & 0.38 & 14998 & 44.05 & 2-Propanamine, 1-methoxy- \\
\hline 2124.470 & 58685 & 0.67 & 13472 & 40.00 & 4-METHYL-5-VINYL THIAZOLE \$S \\
\hline 2224.900 & 59298 & 0.68 & 16955 & 281.00 & ACETYL-ISO-CODEINE \$ \$ \\
\hline \begin{tabular}{|l|l|}
2325.043 \\
\end{tabular} & 58390 & 0.67 & 21221 & 208.05 & Benzo[b]thiophene, 7-ethyl- (CAS) \\
\hline 2425.075 & 21688 & 0.25 & 18040 & 207.00 & Brallobarbital \$\$ 2,4,6(1H,3H,5H)-Py \\
\hline 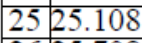 & 105943 & 1.21 & 22346 & 207.00 & 5-Bromo-8-(5-nitrosalicylideneamino) \\
\hline 2625.708 & 169957 & 1.94 & 20749 & 44.05 & .alpha.-D-Galactopyranose, 2-(acetyla \\
\hline 2725.950 & 24049 & 0.27 & 16388 & 44.00 & Thiodipropionic amide $\$ \$$ \\
\hline \begin{tabular}{|l|l|}
28 & 25.983 \\
\end{tabular} & 58208 & 0.66 & 15619 & 73.00 & 9,12,15-Octadecatrienoic acid, 2-[(tri1 \\
\hline \begin{tabular}{|l|l|}
29 & 27.102 \\
\end{tabular} & 53229 & 0.61 & 16094 & 206.95 & 6-Methyl-5-[1-piperidinyl]-2,4-pyrimi \\
\hline 3027.339 & 185802 & 2.12 & 24057 & 207.00 & 2-(N-ethylimino)-3,3-dimethyl-1-ethyl \\
\hline & & & & & \\
\hline
\end{tabular}

Fig 7: Showing the GC-MS Analysis of Ximenia americana leaf extract.

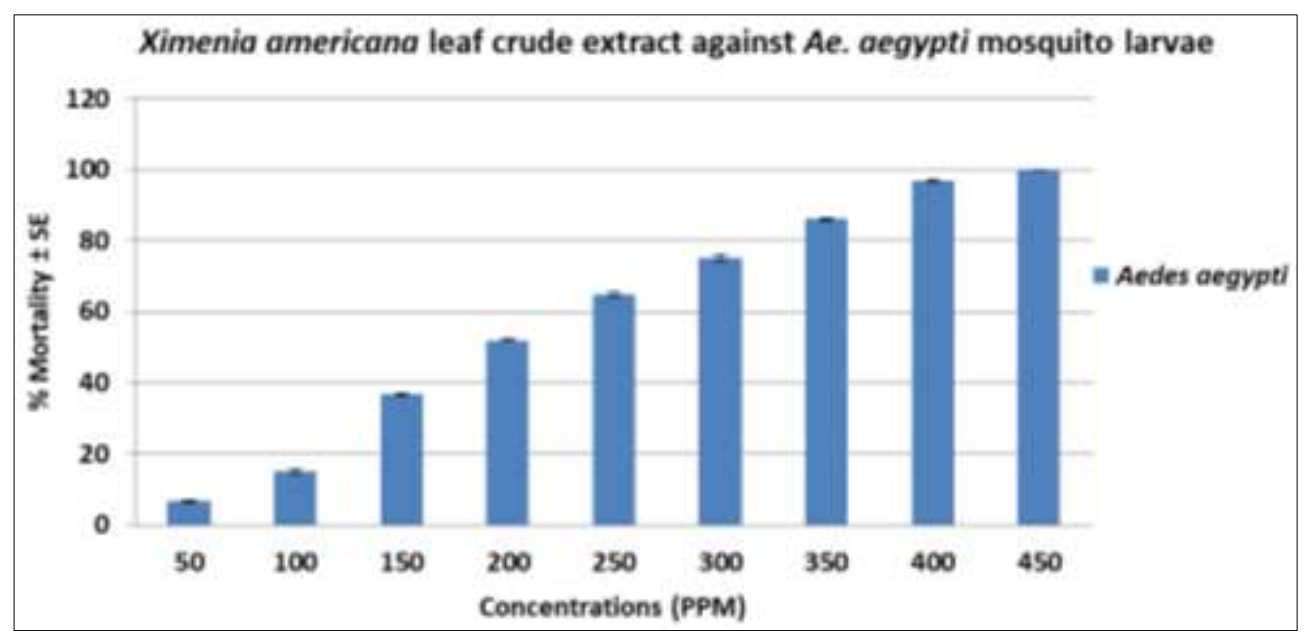

Fig 8: Showing the efficacy of Ximenia americana leaf extract against Ae. aegypti larvae. 


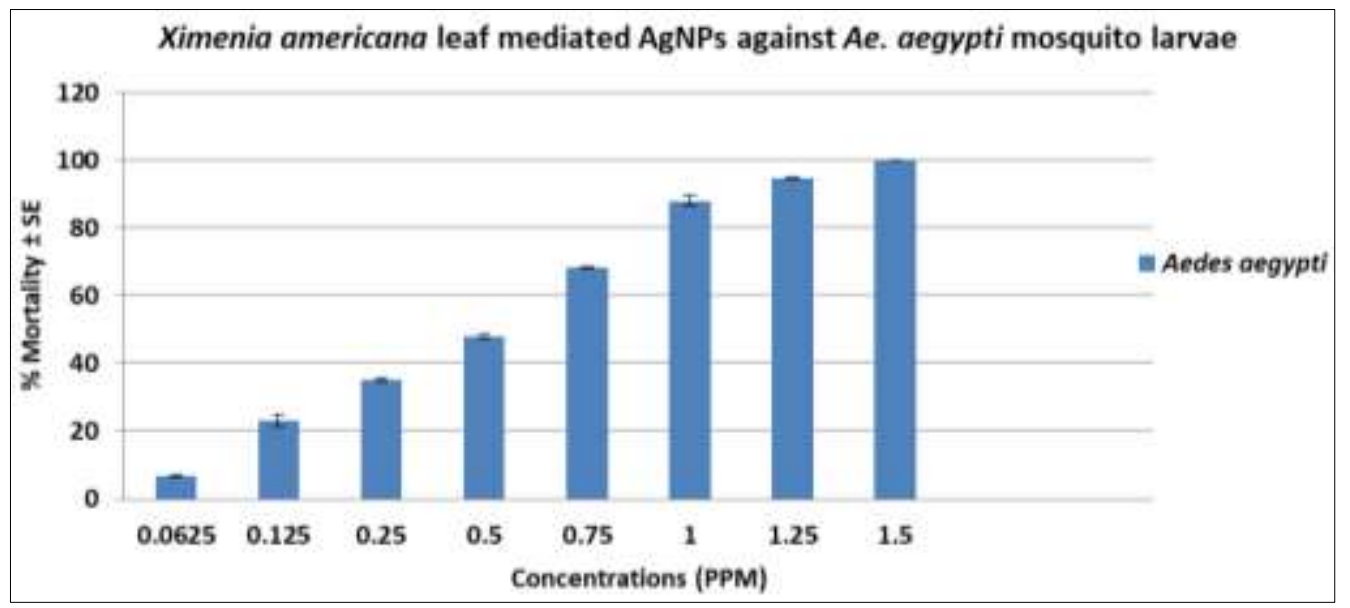

Fig 9: Showing the efficacy tested with Ximenia americana leaf mediated silver nanoparticles against Ae. aegypti.

Table 1: Showing the efficacy of Ximenia americana leaf extract against Ae. aegypti larvae.

\begin{tabular}{|c|c|c|c|}
\hline Extract & Concentrations (in PPM) & Mortality $(\%) \pm$ SE & Lethal concentrations \\
\hline Control & 0 & 0 & \multirow{6}{*}{$\begin{array}{c}\text { LC50 (PPM) (LCL-UCL) } \\
179.87(165.23-194.26)\end{array}$} \\
\hline \multirow{9}{*}{ Plant crude extract } & 50 & $6.67 \pm 0.33$ & \\
\hline & 100 & $15 \pm 0.57$ & \\
\hline & 150 & $36.67 \pm 0.33$ & \\
\hline & 200 & $52 \pm 0.57$ & \\
\hline & 250 & $65 \pm 0.57$ & \\
\hline & 300 & $75 \pm 1$ & \multirow{4}{*}{$\begin{array}{c}\text { LC90 (PPM) (LCL-UCL) } \\
376.77(340.22-428.03)\end{array}$} \\
\hline & 350 & $86 \pm 0.57$ & \\
\hline & 400 & $96.67 \pm 0.33$ & \\
\hline & 450 & 100 & \\
\hline
\end{tabular}

Table 2: Showing the efficacy of Ximenia americana leaf extract mediated silver nanoparticles against Ae. aegyptiI larvae.

\begin{tabular}{|c|c|c|c|}
\hline Extract & Concentrations (in PPM) & Mortality (\%) \pm SE & Lethal concentrations \\
\hline Control & 0 & 0 & \multirow{3}{*}{ LC50 (PPM) (LCL-UCL) } \\
& 0.0625 & $6.67 \pm 0.33$ & 0.63 (0.50-0.78) \\
\cline { 2 - 3 } & 0.125 & $23.33 \pm 1.76$ & \\
\cline { 2 - 3 } & 0.25 & $35 \pm 0.57$ & \\
\cline { 2 - 3 } & 0.5 & $48 \pm 0.57$ & \multirow{2}{*}{ LC90 (PPM) (LCL-UCL) } \\
\cline { 2 - 3 } & 0.75 & $68.33 \pm 0.33$ & 1.20 (0.94-1.68) \\
\cline { 2 - 3 } & 1 & $88 \pm 1.52$ & \\
\cline { 2 - 3 } & 1.25 & $94.67 \pm 0.33$ & 100 \\
\cline { 2 - 3 } & 1.5 & & \\
\cline { 2 - 3 } & & & \\
\end{tabular}

\section{Conclusion}

Use of these botanical derivatives in mosquito control instead of synthetic insecticides could reduce the cost and environmental pollution. Ximenia americana mediated AgNPs could be an alternative source for mosquito larvicides because they constitute a potential source of bioactive chemicals and generally free from harmful effects. These results could encourage the search for new active isolated compounds offering an alternative to synthetic insecticides from other medicinal plants. This research highlighted that the green synthesis of mosquitocidal AgNP using Ximenia americana is an efficient and eco-friendly method against $A e$. aegypti mosquito, and their efficacy in the field is yet to be tested for effective mosquito larval control.

\section{Conflict of interest statement}

The authors declare that there is no conflict of interest.

\section{Authors' contributions}

MS designed, maintained mosquito rearing house, handled experiments, synthesized AgNPs, conducted bioassays, statistical analysis and developed the manuscript. BRN identified the mosquito species, reviewed the literature and contributed to manuscript development. The author(s) read and approved the final manuscript.

\section{Acknowledgements}

We thank the DSA-I (SAP-II) program for providing Laboratory facilities and financial support for work done, research colleagues and also to the Head Department of Zoology, Osmania University, Hyderabad for encouragement and all time support.

\section{References}

1. Reddya Naik B, Swarna Gowreeswari G, Singh Y, Satyavathi R, Daravath SS, Ramachandra Reddy P. BioSynthesis of silver nanoparticles from leaf extract of Pongamia pinnata as an effective larvicide on dengue vector Aedes albopictus (Skuse) (Diptera: Culicidae). Adv Entomol 2014;2:93-101 in SciRes.

2. Khan HA, Akram W, Shehzad K, Shaalan EA. First report of field evolved resistance to agrochemicals in 
dengue mosquito, Aedes albopictus (Diptera: Culicidae), from Pakistan. Parasit Vectors 2011;4:146. Doi: 10.1186/1756-3305-4-146, PMID 21781290.

3. Fonseca-González I, Quiñones ML, Lenhart A, Brogdon WG. Insecticide resistance status of Aedes aegypti (L.) from Colombia. Pest Manag Sci 2011;67(4):430-7. Doi: 10.1002/ps.2081, PMID 21394876.

4. De la Mora-Covarrubias A, Jiménez-Vega F, TreviñoAguilar SM. Geospatial distribution and detection of dengue virus in mosquitoes Aedes (Stegomyia) aegypti in Ciudad Juárez, Chihuahua, México. Salud Publica Mex 2010;52(2):127-33. Spanish. PMID 20485869.

5. World Health Organization. Dengue: guidelines for diagnosis, treatment. Prev Control 2009.

6. Brathwaite Dick O, San Martín JL, Montoya RH, del Diego J, Zambrano B, Dayan GH. The history of dengue outbreaks in the Americas. Am J Trop Med Hyg 2012;87(4):584-93. Doi: 10.4269/ajtmh.2012.11-0770, PMID 23042846.

7. Aziz AT, Al-Shami SA, Mahyoub JA, Hatabbi M, Ahmad AH, Rawi CS. Anupdate on the incidence of dengue gaining strength in Saudi Arabia and current control approaches for its vector mosquito. Parasit Vectors 2014;7(1):258. Doi: 10.1186/1756-3305-7-258, PMID 24890567.

8. Bhatt S, Gething PW, Brady OJ, Messina JP, Farlow AW, Moyes CL, et al. The global distribution and burden of dengue. Nature 2013;496(7446):504-7. Doi: 10.1038/nature12060, PMID 23563266.

9. Brady OJ, Gething PW, Bhatt S, Messina JP, Brownstein JS, Hoen AG, et al. Refining the global spatial limits of dengue virus transmission by evidence-based consensus. PLOS Negl Trop Dis 2012;6(8):e1760. Doi: 10.1371/journal.pntd.0001760, PMID 22880140.

10. NVBDCP. $2019 . \quad$ Available from: https://nvbdcp.gov.in/index4.php?lang=1\&level=0\&linki $\mathrm{d}=431 \&$ lid $=3715$.

11. Gubler DJ. Dengue. In: Monath TP, editor, The arboviruses. Epidemiology and ecology. Boca Raton, FL: CRC Press Press 1998, 223-60.

12. WHO. Report of the WHO informal consultation on the evaluation and testing of insecticides: CTD/WHOPES/IC/96.1. Geneva, Switzerland 1996, 69.

13. David JP, Faucon F, Chandor-Proust A, Poupardin R, Riaz MA, Bonin A, et al. Comparative analysis of response to selection with three insecticides in the dengue mosquito Aedes aegypti using mRNA sequencing. BMC Genomics 2014;15:174. Doi: 10.1186/1471-2164-15-174, PMID 24593293.

14. Brito LP, Linss JG, Lima-Camara TN, Belinato TA, Peixoto AA, Lima JB, et al. Assessing the effects of Aedes aegypti kdr mutations on pyrethroid resistance and its fitness cost. PLOS ONE 2013;8(4):e60878. Doi: 10.1371/journal.pone.0060878, PMID 23593337.

15. Grisales N, Poupardin R, Gomez S, Fonseca-Gonzalez I, Ranson H, Lenhart A. Temephos resistance in Aedes aegypti in Colombia compromises dengue vector control. PLOS Negl Trop Dis 2013;7(9):e2438. Doi: 10.1371/journal.pntd.0002438, PMID 24069492.

16. Mulla MS, Thavara U, Tawatsin A, Chomposri J, Su T. Emergence of resistance and resistance management in field populations of tropical Culex quinquefasciatus to themicrobial control agent Bacillus sphaericus. J Am Mosq Control Assoc 2003;19(1):39-46. PMID 12674533.

17. Benelli G. Research in mosquito control: current challenges for a brighter future. Parasitol Res 2015a;114(8):2801-5. Doi: 10.1007/s00436-015-4586-9, PMID 26093499.

18. Benelli G. Plant-borne ovicides in the fight against mosquito vectors of medical and veterinary importance: a systematic review. Parasitol Res 2015b;114(9):3201-12. Doi: 10.1007/s00436-015-4656-z, PMID 26239801.

19. Isman MB. Botanical insecticides, deterrents, and repellents in modern agriculture and an increasingly regulated world. Annu Rev Entomol 2006;51:45-66. Doi: 10.1146/annurev.ento.51.110104.151146, 16332203.

20. Pelah D, Abramovich Z, Markus A, Wiesman Z. The use of commercial saponin from Quillaja saponaria bark as a natural larvicidal agent against Aedes aegypti and Culex pipiens. J Ethnopharmacol 2002;81(3):407-9. Doi: 10.1016/s0378-8741(02)00138-1, PMID 12127245.

21. Murugan K, Murugan P, Noortheen A. Larvicidal and repellent potential of Albizzia amara Boivin and Ocimum basilicum Linn against dengue vector, Aedes aegypti (Insecta:Diptera:Culicidae). Bioresour Technol 2007;98(1):198-201. Doi: 10.1016/j.biortech.2005.12.009, PMID 16473002.

22. Rahuman AA, Venkatesan P. Larvicidal efficacy of five cucurbitaceous plant leaf extracts against mosquito species. Parasitol Res 2008;103(1):133-9. Doi: 10.1007/s00436-008-0940-5, PMID 18340464.

23. Bagavan A, Rahuman AA, Kamaraj C, Geetha K. Larvicidal activity of saponin from Achyranthes aspera against Aedes aegypti and Culex quinquefasciatus (Diptera: Culicidae). Parasitol Res 2008;103(1):223-9. doi: 10.1007/s00436-008-0962-z, PMID 18392726.

24. Zahir AA, Rahuman AA, Kamaraj C, Bagavan A, Elango G, Sangaran A, et al. Laboratory determination of efficacy of indigenous plant extracts for parasite control. Parasitol Res 2009;105(2):453-61. Doi: 10.1007/s00436009-1405-1, PMID 19308453.

25. Benelli G, Lukehart CM. applications of greensynthesized nanoparticles in pharmacology, parasitology and entomology. J Clust Sci 2017;28(1):1-2. Doi: 10.1007/s10876-017-1165-5.

26. Azarudeen RMST, Govindarajan M, Amsath A, Muthukumaran U, Benelli G. Single-step biofabrication of silver nanocristals using Naregamia alata: a cost effective and eco-friendly control tool in the fight against malaria, Zika virus and St Louis encephalitis mosquito vectors. J Clust Sci 2017;28(1):179-203. Doi: 10.1007/s10876-016-1067-y.

27. Roni M, Murugan K, Panneerselvam C, Subramaniam J, Nicoletti M, Madhiyazhagan $\mathrm{P}$, et al. Characterization and biotoxicity of Hypnea musciformis-synthesized silver nanoparticles as potential eco-friendly control tool against Aedes aegypti and Plutella xylostella. Ecotoxicol Environ Saf 2015;121:31-8. Doi: 10.1016/j.ecoenv.2015.07.005, PMID 26184431.

28. Kumar B, Angulo Y, Smita K, Cumbal L, Debut A. Capuli cherry-mediated green synthesis of silver nanoparticles under white solar and blue LED light. Particuology 2016;24:123-8. Doi: 10.1016/j.partic.2015.05.005.

29. Kumar B, Smita K, Cumbal L, Angulo Y. Fabrication of silver nanoplates using Nephelium lappaceum (Rambutan) peel: a sustainable approach. J Mol Liq 2015b;211:476-80. Doi: 10.1016/j.molliq.2015.07.067.

30. Silver JB. Mosquito ecology: field sampling methods. 3rd 
ed. ISBN 978-1-4020-6665-8 (HB) 2008.

31. Gerberc EJ. Manual for mosquito rearing and experimental techniques. AMCA Bulletin no. 05. Baltimore: American Mosquito Control Association, Inc 1970, 1-91.

32. Tyagi BK, Munirathinam A, Krishnamoorthy R, Venkatesh A. A field-based handbook of identification keys to mosquitoes of public health importance in India. Madurai. Cent Res Med Entomol 2012.

33. Barraud PJ. Family Culicidae, Tribes Megarhinini and Culincini, The fauna of British India, Including Ceylon and Burma- Diptera Taylor and Francies, London 1934;5:1-463.

34. Christophers SR. Family Culicidae. Tribes Anophelini. The fauna of British India, including Ceylon and Burma 0 Diptera. London: Taylor \& Francis 1933;4:1-271.

35. Banerjee P, Satapathy M, Mukhopahayay A, Das P. Leaf extract mediated green synthesis of silver nanoparticles from widely available Indian plants: synthesis, characterization, antimicrobial property and toxicity analysis. Bioresour Bioprocess 2014;1(1):3. Doi: 10.1186/s40643-014-0003-y.

36. Handa SS, Khanuja SPS, Longo G, Rakesh DD. Extraction. Trieste: Technologies for Medicinal and Aromatic Plants, International Centre for Science and High Technology 2008.

37. Nalini M, Lena M, Sumathi P, Sundaravadivelan C. Effect of phyto-synthesized silver nanoparticles on developmental stages of malaria vector, Anopheles stephensi and dengue vector, Aedes aegypti. Egypt J Basic Appl Sci 2017;4(3):212-8. Doi: 10.1016/j.ejbas.2017.04.005.

38. Suresh G, Gunasekar PH, Kokila D, Prabhu D, Dinesh D, Ravichandran Nagaiya, et al. Green synthesis of silver nanoparticles using Delphinium denudatum root extract exhibits antibacterial and mosquito larvicidal activities. Spectrochim Acta A Mol Biomol Spectrosc 2014;127:616. Doi: 10.1016/j.saa.2014.02.030, PMID 24632157.

39. Velayutham K, Rahuman AA, Rajakumar G, Roopan SM, Elango G, Kamaraj C, et al. Larvicidal activity of green synthesized silver nanoparticles using bark aqueous extract of Ficus racemosa against Culex quinquefasciatus and Culex gelidus. Asian Pac J Trop Med 2013;6(2):95101. Doi: 10.1016/S1995-7645(13)60002-4, PMID 23339909.

40. Roopan SM, Rohit G, Madhumitha A, Abdul Rahuman, Kamaraj C, Bharathi A, et al. Low-cost and eco-friendly phyto-synthesis of silver nanoparticles using Cocos nucifera coir extract and its larvicidal activity. Industrial Crops and Products 2013;43631-635.

41. WHO. Guidelines for laboratory and field testing of mosquito larvicides. WHO/CDS/WHOPES/GCDPP 2005;13:10-2.

42. Reddy PJ, Krishna D, Murty US, Jamil K. A microcomputer FORTRAN Program for Rapid Determination of Lethal Concentration of Biocides in mosquito control. Comput Appl Biosci 1992;8(3):209-13. Doi: 10.1093/bioinformatics/8.3.209, PMID 1353007.

43. Shahi M, Hanafi-Bojd AA, Iranshahi M, Vatandoost H, Hanafi-Bojd MY. Larvicidal efficacy of latex and extract of Calotropis procera (Gentianales: Asclepiadaceae) against Culex quinquefasciatus and Anopheles stephensi (Diptera: Culicidae). J Vector Borne Dis 2010;47(3):1858. PMID 20834091.
44. Saxena RC, Harshan V, Saxena A, Sukumaran P, Sharma MC, Kumar ML. Larvicidal and chemosterilant activity of Annona squamosa alkaloids against Anopheles stephensi. J Am Mosq Control Assoc 1993;9(1):84-7. PMID 8468579.

45. Santhoshkumar T, Rahuman AA, Rajakumar G, Marimuthu S, Bagavan A, Jayaseelan C, et al. Synthesis of silver nanoparticles using Nelumbo nucifera leaf extract and its larvicidal activity against malaria and filariasis vectors. Parasitology Research 2011;108(3):693-702. https://doi.org/10.1007/s00436010-2115-4

46. Paramasivam Deepak, Rajamani Sowmiya, Govindasamy Balasubramani, Dilipkumar Aiswarya, Dhayalan Arul, Muthu Paulraj Diviya Josebin, et al. Mosquito-larvicidal efficacy of gold nanoparticles synthesized from the seaweed, Turbinaria ornata (Turner) J.Agardh 1848. Particulate Science and Technology 2018;36(8):974-980.

47. Azarudeen RMST, Govindarajan M, AlShebly MM, AlQahtani FS, Amsath A, Senthilmurugan S, et al. Sizecontrolled biofabrication of silver nanoparticles using the Merremia emarginata leaf extract: Toxicity on Anopheles stephensi, Aedes aegypti and Culex quinquefasciatus (Diptera: Culicidae) and non-target mosquito predators. Journal of Asia-Pacific Entomology 2017b;20(2):359-366. doi:10.1016/j.aspen.2017.02.007

48. Govindarajan M, Kadaikunnan S, Alharbi N, Benelli G. Single-step biological fabrication of colloidal silver nanoparticles using Hugonia mystax: larvicidal potential against Zika virus, dengue, and malaria vector mosquitoes. Artificial Cells, Nanomedicine And Biotechnology 2016m;45(7):1317-1325. https://doi.org/10.1080/21691401.2016.1228664

49. Sutthanont N, Attrapadung S, Nuchprayoon S. Larvicidal activity of synthesized silver nanoparticles from Curcuma zedoaria essential oil against Culex quinquefasciatus. Insects 2019;10(1):27. doi:10.3390/insects10010027

50. Aina DA, Owolo O, Lateef A, Aina FO, Hakeem AS, Adeoye-Isijola M, et al. Biomedical applications of Chasmanthera dependens stem extract mediated silver nanoparticles as antimicrobial, antioxidant, anticoagulant, thrombolytic, and larvicidal agents. Karbala International Journal of Modern Science 2019;5(2):2. doi:10.33640/2405-609X.1018

51. Benelli G, Kadaikunnan S, Alharbi NS, Govindarajan M. Biophysical characterization of Acacia caesia-fabricated silver nanoparticles: Effectiveness on mosquito vectors of public health relevance and impact on non-target aquatic biocontrol agents. Environmental Science and Pollution Research International 2018a;25(11):10228-10242. doi:10.1007/s11356-017-8482-y

52. Muthukumaran U, Govindarajan M, Rajeswary M, Hoti SL. Synthesis and characterization of silver nanoparticles using Gmelina asiatica leaf extract against filariasis, dengue, and malaria vector mosquitoes. Parasitology Research 2015b;114(5):1817-1827. doi:10.1007/s00436015-4368-4

53. Mondal A, Hajra A, Shaikh WA, Chakraborty S, Mondal Naba K. Synthesis of silver nanoparticle with Colocasia esculenta (L.) stem and its larvicidal activity against Culex quinquefasciatus and Chironomus sp. Asian Pacific Journal of Tropical Biomedicine 2019;9(12):510517. doi:10.4103/2221-1691.271724 